\title{
Past, Present, Future
}

\author{
Steven N. Handel
}

\section{The Past}

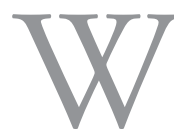

e live in a fractured world. Old biotic patterns and relationships have changed with the growth of human activities and their consequences. This is not a new phenomenon, but one that has always accompanied the activities of our populations. Here, in North America, since the first people crossed over from Asia, plant and animal communities and ecosystem processes have been modified, sometimes dramatically, for thousands of years (Krech 1999). More recently, the past few hundred years have shown an escalating rate of change of our living environment (Whitney 1994). Signs of human modifications to ecological structure and function are everywhere around us, from the landscape fragmentation of once continuous habitats (Forman 1995), to the changes in the diversity of species that surround us (Sax et al. 2005), to the more subtle signs of past human uses in the woodlots and farms of our countryside and suburbs (Egan and Howell 2001, Wessels 2010).

These changes are accelerating with the rapid growth of the human population, urbanization of these populations throughout the world, and the continuing spread of suburbs around large cities. Other drivers of this change are our frantic travels, now faster, cheaper, and more frequent than in the past. As we move about the globe, we facilitate the movement of many species of plants, insects, and marine invertebrates that modify our habitats and tend to eliminate more species than are being introduced.

A fundamental goal of restoration ecology is to identify, as best we can, past patterns of ecological structure and to determine the appropriate and pragmatic target, even in the many cases when the old patterns are impossible to reiterate.

\section{The Present}

We are all surrounded by a new biota, different species and in different community relationships from those seen in the past. This is been called a "synthetic vegetation" (Bridgewater 1990), containing elements of the past but with new species that together function in ways that are just now

Ecological Restoration Vol. 29, No. 3, 2011

ISSN 1522-4740 E-ISSN 1543-4079

(C2011 by the Board of Regents of the University of Wisconsin System. being described (Hobbs et al. 2009). These strange new communities and the remnants of the old both support our civilization in many ways. Sustainable habitats can supply better air and water quality and the diversity that supports agricultural success and other commercial enterprises. It is unclear how "synthetic vegetation" performs, although all carbon sequestration is treasured in these days. These functions now have an appreciative audience for what are termed ecological services. This is now playing a major role in tying the science of ecology to economic concerns and public policy initiatives (Daily 1997). Nature is all around us, but in addition to its cultural values, it is needed, and is appreciated in new ways. For example, our urban planners increasingly seek ecological solutions to improve conditions in our city centers. Even the United States Forest Service, traditionally focused on our wild lands, has a strong urban forestry interest. Long-practiced restoration in rural areas increasingly has a city cousin.

In these ways the practice of restoration ecology is growing and being seen as more important to all landscapes. Our discipline is based in nature study, environmental management, and the traditional concerns of ecological science. But it is now overlapping with other disciplines and other professional groups. Initiatives in restoration ecology are happening at the large-scale, such as the Everglades and the Gulf Coast of the United States, and also at the small local scale such as in community gardens and in town woodlots.

The founder of this journal, Bill Jordan, had the vision to see that restoration ecology was not just another level of organization within biology, but something much grander (Jordan et al. 1987). His influence and perspective molded the mission of this journal and continues to make its contents much different from our partner journals in ecological science. Any issue of this journal as well as the proceedings of the annual meetings of the Society for Ecological Restoration International shows that the interests of practitioners, though often based in ecology, involve so many other concerns. These range from community organizing, to reordering local government concerns, to the preferred genetic structure of restored populations, and the management of newly created natural communities. This field is inclusive of disciplines once far removed from a field ecologist's daily concerns. 


\section{The Future}

The trajectory of ecological change is rising. Human population growth is continuing, climate change is increasing, and urbanization is now the norm for the world's populated areas. These forces are inseparable from the activities of restoration ecology practitioners. Holding on to ecological structure and function that remains will be even more difficult surrounded by the whirling change that accompanies these human driven processes. How can we advance the practice of ecological restoration? How can this journal and its mission play the best role in this advance? In my own work, I have had the honor of focusing first on individual plants and their population processes, then on the construction and restoration of new communities on small-scale degraded land, and then participating in the design of restored habitats and civic activities on very large public park projects. My attempts at public education have been addressed to age groups from eight-year-old Cub Scouts through high school and university students, to public audiences of adults throughout this country. I am aware that restoration ecology is as complex as the living communities we dream about, involving both the natural history of the organisms that we study to the human ecology of the people with whom we must work. We will try to bring these many perspectives to the new task of editing these pages.

First, ecological science must continue to grow and be reported in these pages. We must continue to publish articles, notes, and ideas applying these principles to the changing landscape. Louis Pasteur's famous stance, that nothing can give more satisfaction to a scientist than making new discoveries, but that the cup of joy is full only when those discoveries lead to practical application, is a fine foundation for the scientific work we report here. Pasteur's early research was solidly in ecology (Duclaux 1920). Understanding, acting upon, and educating about ecological progress will always be a foundation of this journal's mission.

Second, we see that restoration ecology must build new bridges to other disciplines not often represented at our meetings and discussions. Whenever ecologists learn about natural processes, they will not be expressed on the land unless we partner with the design professions who have the authority to sign and seal the blueprints necessary for landscape change. Architects, landscape architects, civil engineers, and licensed planners will all play a necessary role if restoration ecology is going to be more widely used in the future of our landscapes. We must find new ways to facilitate these dialogues, and this journal must play a part. Starting with this issue we will have a new section entitled "Design Approaches to Ecological Restoration." These articles will usually be written by design professionals who have a deep ecological interest. They will suggest novel ways of building our world that closely incorporate ecological principles. We will follow each article with a commentary from someone within the ecological world, giving critiques and perspective. The design professions can march with us to a healthier future.

Third, we must continue to develop outreach and educational modes to better incorporate restoration ecology into the Academy and into our public policy dialogue. New courses at all levels, from universities and public schools, to continuing education programs and youth activities must be encouraged. We will find room here to express new educational ideas and experiments that can be reiterated throughout the restoration world.

The great restoration ecologist from the University of Liverpool, Tony Bradshaw, once wrote that restoration is the acid test of ecological theory (Bradshaw 1983). He meant that if we really understood the natural world we should be able to rebuild it from scratch, just as our partners from the world of genetics can rebuild macromolecules from small chemical pieces. This is a great challenge for restoration scientists, to get closer and closer to our dream of truly restoring ecological function.

There is urgency in this quest which is a spinoff from the Red Queen hypothesis of evolution (Van Valen 1973). That hypothesis, taken from the story of Alice Through the Looking Glass, states that one must move as fast as one can just to stay in the same place. Although this is used in evolutionary science as a conceptual tool, it also is central to our ecological work. G. E. Hutchinson pictured our world as an ecological theater with an evolutionary play (Hutchinson 1965). In our fast changing environment, the importance of restoration ecology must enlarge and quicken if we are going to keep pace with environmental change and deliver the ecological services upon which we all depend. We can only hope that this journal is carried with you all, as we race together towards this goal.

\section{References}

Bradshaw, A. D. 1983. The reconstruction of ecosystems. Journal of Applied Ecology 20:1-17.

Bridgewater, P. B. 1990. The role of synthetic vegetation in present and future landscapes of Australia. Proceedings of the Ecological Society of Australia 16:129-134.

Daily, G. 1997. Nature's Services: Societal Dependence on Natural Ecosystems. Washington DC: Island Press.

Duclaux, E. 1920. Pasteur, the History of a Mind. Philadelphia PA: Saunders.

Egan, D. and E.A. Howell (eds). 2001. The Historical Ecology Handbook: A Restorationist's Guide to Reference Ecosystems. Washington D.C.: Island Press.

Forman, R. T. T. 1995. Land Mosaics, The Ecology of Landscapes and Regions. Cambridge UK: Cambridge University Press.

Hobbs, R. J., E. Higgs and J.A. Harris. 2009. Novel ecosystems: implications for conservation and restoration. Trends in Ecology and Evolution 24: 599-605.

Hutchinson, G. E. 1965. The Ecological Theater and the Evolutionary Play. New Haven CT: Yale University Press. 
Jordan, W.R., III, M.E. Gilpin and J. D. Aber. 1987. Restoration Ecology, a Synthetic Approach to Ecological Research. Cambridge UK: Cambridge University Press.

Krech, S. 1999. The Ecological Indian, Myth and History. New York: W.W. Norton.

Sax, D. F., J. J. Stachowicz and S. D. Gaines (eds). 2005. Species Invasions, Insights into Ecology, Evolution, and Biogeography. Sunderland MA: Sinaur Associates.
Van Valen, L. M. 1973. A new evolutionary law. Evolutionary Theory 1: 1-30.

Wessels, T. 2010. Forest Forensics, a Field Guide to Reading the Forested Landscape. Woodstock VT: Countrymen Press.

Whitney, G. G. 1994. From Coastal Wilderness to Fruited Plain, a History of Environmental Change in Temperate North America 1500 to the Present. Cambridge UK: Cambridge University Press. 